\title{
Study on Contact Force Relaxation Behavior of Mortise- and-Tenon Joints Considering Tenon Fits and Grain Orientations of Tenon
}

\author{
Wen Gang Hu, ${ }^{\mathrm{a}}$ Hui Wan, ${ }^{\mathrm{b}}$ and Hui Yuan Guan ${ }^{\mathrm{a}, *}$ \\ A new method of testing mechanical properties of mortise-and-tenon \\ joints is put forward. The contact force relaxation behavior of joints for 3 \\ $\mathrm{h}$ with tenons in different grain orientations and tenon fits were studied. \\ The results showed that the initial and final contact force of joints with \\ tenons in radial grain orientation were all larger than those in tangential \\ grain orientation in the same tenon fit. The regression equations \\ generated in this paper were able to predict the contact force relaxation \\ behavior of joints with tenons in different grain orientations, tenon fits, \\ and time, and the errors were all within $20 \%$. In addition, the ratio of loss \\ for contact force of joints with tenons in radial grain orientations was \\ greater than that with tenons in tangent in the same tenon fit. The ratios \\ of loss decreased from $51 \%$ to $31 \%$ in two grain orientations of tenon \\ with tenon fits increasing from $0.2 \mathrm{~mm}$ to $0.5 \mathrm{~mm}$ with an increment of \\ $0.1 \mathrm{~mm}$. The method proposed in this paper was able to predict the \\ contact force relaxation of mortise-and-tenon joints. The relaxation of \\ contact force in a joint should be considered when designing mortise- \\ and-tenon joint furniture.
}

Keywords: Mortise-and-tenon; Furniture joints; Contact force; Relaxation

Contact information: a: Department of Furniture design, Nanjing Forestry University, 210037 Nanjing, China; b: Department of Sustainable Bioproducts, Mississippi State University, Mississippi State, MS 39762-9820, United States; *Corresponding author: hwg@njfu.edu.cn

\section{INTRODUCTION}

Mortise-and-tenon joints are widely applied in solid wood frame furniture. Many researchers have studied the factors that influence the strength of joints, including tenon fit (Zhong and Guan 2007), glue types, wood species (Smardzewski 2002; Ratnasingam and Iorasn 2013), tenon shape and geometry (Sparkes 1968; Hill and Eckelman 1973; Erdil et al. 2005; Tankut and Tankut 2005; Kasal et al. 2016), and their composed factors (Zaborsky et al. 2017) with T-shaped and L-shaped specimens. Then the tension load resistance and bending moment capacity were usually used to evaluate the joint strength. However, these testing results were all instantaneous experimental values, which ignored the long-term contact force relaxation behavior of the joint.

The strength of furniture does not rely on the member itself but the joint (Eckelman 1971; Smardzewski and Lewandowski 2014; Li et al. 2014; Hu et al. 2017), and it is usually subjected to tension and shear load during daily usage. The strength of the joint is determined by contact force and bonding strength of the joint, and the contact force plays an important role. However, the contact force of the joint is unknown and not a constant. Rather it varies with the time for the viscoelasticity of wood (i.e., the contact force decreases with time for relaxation of the joint). Thus, the influences of contact force 
relaxation on the strength of the joint should be accounted for in mortise-and-tenon joint furniture design. However, there are few relevant studies on them due to lack of efficient testing methods.

$\mathrm{Hu}$ and Guan (2017a) set up a mathematical model to predict the contact force of oval mortise-and-tenon joint in elastic range of wood by simplifying the mortise-andtenon joint as a 2D arc line. Firstly, the differentiation method was used to divide the arc line into finite discrete point; then the maximum contact force was figured out by elastic mechanics. Secondly, the formula of arc line was fitted by elliptic equation. Finally, the total contact force were able to be calculated by integral to the arc line function. Furthermore, they also investigated the friction coefficient of mortise and tenon joints by experimental methods (Hu and Guan 2017b). Thus, the withdrawal forces of mortise-andtenon were determined based on Coulomb's law of friction. Besides, the result of the mathematical model was compared with that of the experiment and FEM. The results showed that mathematical model was consistent with the experiment and FEM.

Mechanical properties of mortise-and-tenon joint, such as tension load resistance and bending moment capacity, are always accompanied by contact force relaxation behaviour, which seriously influences the long-term mechanical properties of wood construct and wood furniture. Diler et al. (2017) investigated the withdrawal force capacity of T-type furniture joints constructed from various heated-treated wood species. The results showed that heat treatment reduced the withdrawal force capacity of joints by $25 \%$ compared with the joints constructed of control specimens. Since the heat treatment accelerated the contact force relaxation of mortise-and-tenon joint, it also suggested that the contact force relaxation behaviour decreased the strength of joint. Besides, many studies (Tankut and Tankut 2005; Zhong and Guan 2007; Kasal et al. 2016) indicated that the bending and tension strength of mortise-and-tenon joint furniture increased with the growth of the tenon fits. In fact, the root of this trend was that contact force increased with tenon fits, so determination of the contact force was necessary.

Using the finite element method to analyze the mortise-and-tenon joint furniture (Smardzewski and Papuga 2004; Mohammad and Ghanbar 2014; Wang and Lee 2014) has also been a highlight. However, the contact force relaxation behavior was not considered, so the results of FEM are usually larger than that of experiment. Although FEM can be applied to study mechanics of mortise and tenon joints to some extent, the accuracy was not ensured, since no experimental test was carried out to prove it.

Overall, the contact force relaxation behaviour plays an important role in mortiseand-tenon joint furniture. In this paper, a method was designed to test the mechanical properties of oval mortise-and-tenon joints. It was then applied to determine the contact force relaxation behavior of joints influenced by tenon fits of joint and grain orientations of tenons. This new method can help us know more about the strength of mortise-andtenon joint furniture.

\section{EXPERIMENTAL DESIGN}

\section{Material and Equipment}

Beech material (Fagus orientalis Lipsky) was purchased from a local wood commercial supplier (Nanjing, China). The average density was $0.629 \mathrm{~g} / \mathrm{cm}^{3}$, and the moisture content was conditioned to and held at $10.8 \%$ before and during experiments. 


\section{Description of Specimens}

All specimens were processed by a computer numerical control machine with accuracy of $0.01 \mathrm{~mm}$ (WPC; YULI; China). Firstly, mortises and tenons were machined in the same size (mortise: $30 \mathrm{~mm}$ deep $\times 30 \mathrm{~mm}$ long $\times 16 \mathrm{~mm}$ wide, tenon: $30 \mathrm{~mm}$ long $\times 30 \mathrm{~mm}$ height $\times 16 \mathrm{~mm}$ thick). Secondly, mortises were divided into the two same parts by saw with a $4 \mathrm{~mm}$ thick blade. Then, all burrs of specimens were sanded by sandpaper carefully to make sure that the mortise and tenon could be assembled seamlessly. The dimensions of specimen are shown in Fig. 1, and the grain orientations in wide directions of tenon were categorized into radial and tangential. The grain orientation in wide direction of tenons shown in Fig. 1 was defined as radial, and the tangential direction was perpendicular to it. All specimens were stored in a constant temperature and humidity case before testing.

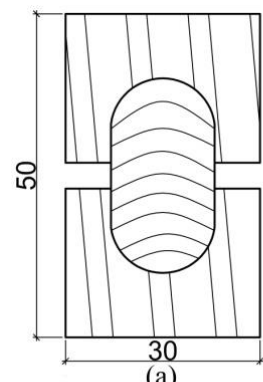

(a)

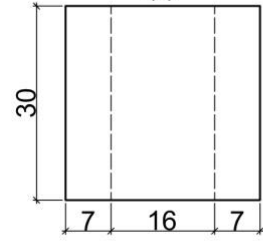

(c)

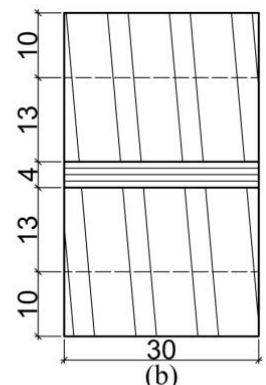

(b)

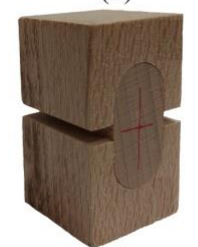

(d)

Fig. 1. Dimensions of specimen (i.e., the front view is Fig. 1-a, the left view is Fig. 1-b, the top view is Fig. 1-c and the photo of specimen is Fig. 1-d)

\section{Testing Methods}

The main equipment used in the experiment was a $20 \mathrm{kN}$ universal testing machine (AGS-X; SHIMADZU; Japan) with a steel mould designed by the authors. The detailed dimensions of the mould are shown in Fig. 2.
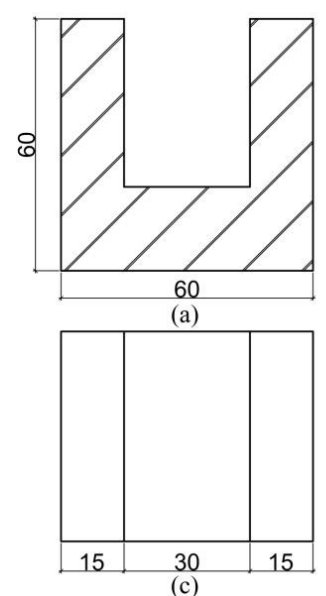

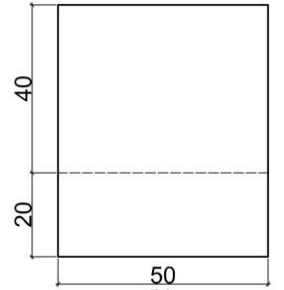

(b)

Fig. 2. Dimensions of steel mould (i.e., the front view is Fig 2-a, the left view is Fig 2-b and the top view is $2-c)$ 
This method was put forward based on the thought of approximate equivalence. The contact force between mortise and tenon results from the interference fit (i.e., interference fit is in wide direction of tenon, and clearance fit is in thick direction of tenon). Thus the contact force mainly exists in the wide direction of the joint. It is difficult to measure the contact force in the assembled state of mortise-and-tenon joint, so the method in this paper was put forward (the displacement of universal test machine is equal to the interference fit between mortise-and-tenon joint, then the load outputted by machine is close to the contact force of the mortise-and-tenon joint). The testing method is shown in Fig. 3, and the specimen was configured with the mould. Firstly, a $10 \mathrm{~N}$ preload was imposed on the specimen to bring the mortise and tenon into close contact. Secondly, the universal test machine was used to apply increasing load until reaching the displacement specified, and then the displacement was maintained at a constant for $3 \mathrm{~h}$. Finally, the contact force relaxation behavior of joint was recorded by the testing machine. In this study, the displacement was set as $0.2 \mathrm{~mm}, 0.3 \mathrm{~mm}, 0.4 \mathrm{~mm}$, and 0.5 $\mathrm{mm}$, which corresponded to the tenon fits in mortise-and-tenon joints. The loading speed was $0.5 \mathrm{~mm} / \mathrm{min}$, and 40 measurements were conducted for four tenon fits of joints and two grain orientations of tenons.

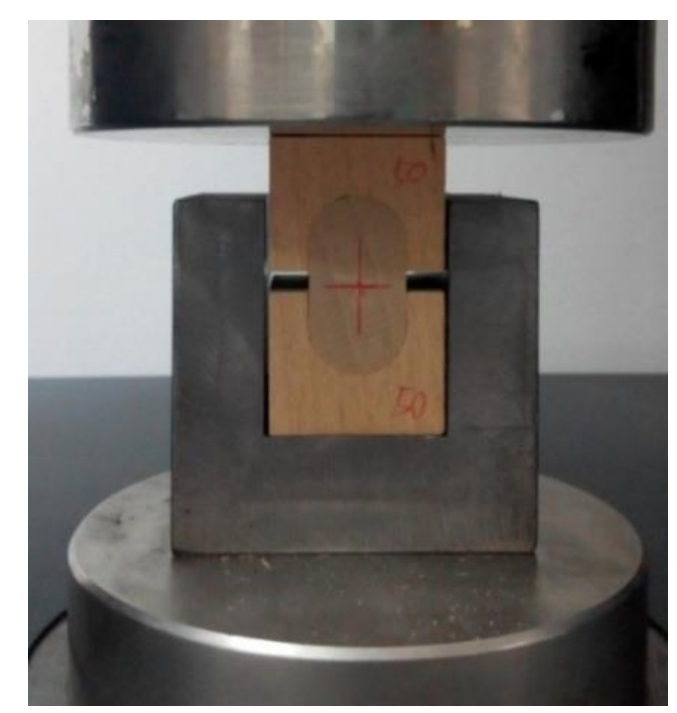

Fig. 3. The testing method of contact force relaxation behavior

\section{RESULTS AND DISCUSSION}

\section{Influence of Tenon Fit on Contact Force Relaxation}

The results of contact force relaxation behavior of joints with different tenon fits are shown in Fig. 4, and the grain orientation in wide direction of tenon was radial. The initial contact force increased with the growth of tenon fits. The contact force of joints decreased with the increase of time, but the slope tended to be stable. In addition, relationships between contact force of joints and time with different tenon fits were fitted, as shown in Eqs. 1, 2, 3, and 4. The correlation coefficients were all beyond 0.99, which suggested that they were able to predict the contact force relaxation behavior of joints with time increasing in corresponding tenon fits. 


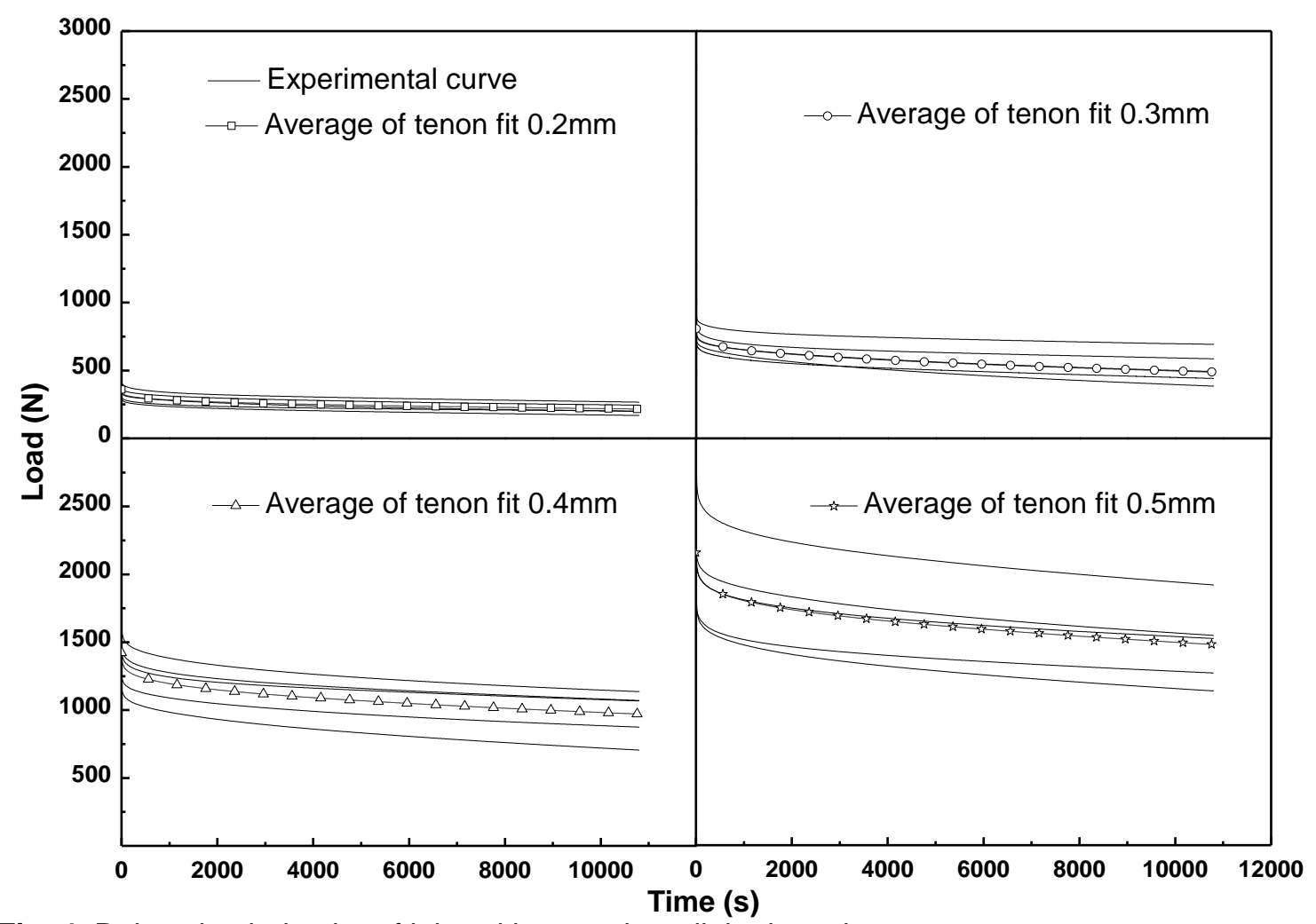

Fig. 4. Relaxation behavior of joint with tenon in radial orientation

$$
\begin{array}{ll}
\mathrm{F}_{(t)}^{0.2}=202+94 \mathrm{e}^{-t / 6138}+51 \mathrm{e}^{-t / 183} & \mathrm{R}^{2}=0.99485 \\
\mathrm{~F}_{(t)}^{0.3}=441+242 \mathrm{e}^{-t / 6913}+103 \mathrm{e}^{-t / 142} & \mathrm{R}^{2}=0.99699 \\
\mathrm{~F}_{(t)}^{0.4}=906+331 \mathrm{e}^{-t / 7035}+153 \mathrm{e}^{-t / 166} & \mathrm{R}^{2}=0.99634 \\
\mathrm{~F}_{(t)}^{05}=1388+474 \mathrm{e}^{-t / 6879}+251 \mathrm{e}^{-t / 158} & \mathrm{R}^{2}=0.99639
\end{array}
$$

In order to get a general equation to predict the contact force of joints in different tenon fits and time, Eqs. 1 through 4 were combined into Eq. 5 by fitting the corresponding item in the same location of four equations and different tenon fits. On inspection, the results of Eq. 5 were consistent with those of the experiment, and the errors were within $20 \%$,

$$
\mathrm{F}_{(t)}^{(x)}=-674+4023 x+(-145+1299 x) \mathrm{e}^{-t / 6741}+(-88+650 x) \mathrm{e}^{-t / 162}
$$

where $F$ refers to contact force of joint $(\mathrm{N}) ; x$ refers to tenon fit of joint $(\mathrm{mm}) ; t$ refers to relaxation time (s).

Figure 5 shows the contact force relaxation behavior of joints with the grain orientation in wide direction of tenons in tangent. The initial contact force of joints had the same trends with tenons in radial grain orientation with the growth of tenon fits. Equation 6 was based on the same fitting method applied to joints with tenons in radial grain orientation. It was capable of predicting the contact force of joints with tenons in tangential directions with the increase of time, and the errors were also within $20 \%$. 


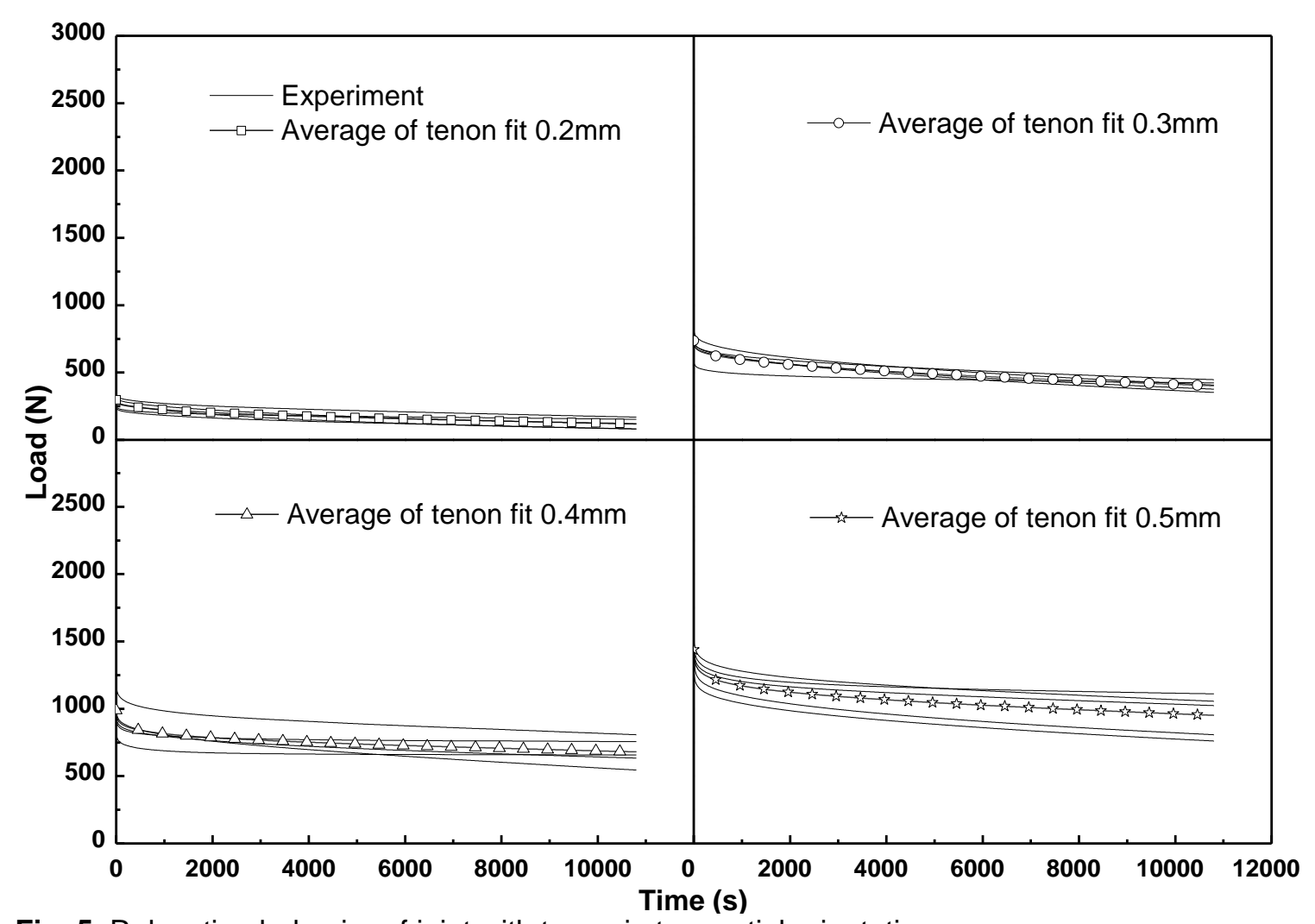

Fig. 5. Relaxation behavior of joint with tenon in tangential orientation

$$
\begin{aligned}
& \mathrm{F}_{(t)}^{(x)}=-486+2775 x+(-58+486 x) \mathrm{e}^{-t /\left(164+4899 * 1.2 \mathrm{e}^{-8}\right)}+[243+78 * \\
& \left.\sin \left(\pi \frac{x-0.05}{0.1}\right)\right] \mathrm{e}^{-t / 7410}
\end{aligned}
$$

where $F$ refers to contact force of joint $(\mathrm{N}) ; x$ refers to tenon fit of joint $(\mathrm{mm})$; and $t$ refers to relaxation time $(\mathrm{s})$.

\section{Influence of Grain Orientation on Contact Force Relaxation}

The results of contact force of joints in radial and tangential grain orientations are compared in Table 1. The results suggest that the initial and final contact force of joints all increased with the growth of tenon fits in joints with tenons in radial and tangential grain orientations. The initial and final contact forces of joints with tenons in radial grain orientations were all bigger than those with tenon in tangential grain orientation in the same tenon fits. Because the directions of rays were parallel to the radial grain orientations, the stiffness of wood in radial orientations was greater than those in tangential (Hu and Guan 2017c). In addition, after $3 \mathrm{~h}$ of relaxation, the loss of contact forces increased with tenon fit growth, but the ratio of losses decreased. Meanwhile, the ratio of losses for joints with tenons in tangential grain orientations was larger than those in radial, especially, when the tenon fit was $0.2 \mathrm{~mm}$ and $0.3 \mathrm{~mm}$. The bigger the tenon fit was in joint, the more densified the tenon was. Thus, the elasticity was not able to recover completely when the wood was in the plastic stage, so the ratio of loss decreased with the tenon fits increasing. 
Table 1. Comparison of Contact Force in Joints with Tenon in Radial and Tangential Orientations

\begin{tabular}{|c|c|c|c|c|c|c|c|c|}
\hline $\begin{array}{c}\text { Tenon } \\
\text { Fit }\end{array}$ & \multicolumn{2}{|c|}{$\begin{array}{l}\text { Initial Contact Force } \\
\text { (COV) }\end{array}$} & \multicolumn{2}{|c|}{$\begin{array}{c}\text { Final Contact Force } \\
(\mathrm{COV})\end{array}$} & \multicolumn{2}{|c|}{ Loss (COV) } & \multicolumn{2}{|c|}{$\begin{array}{c}\text { Ratio of } \\
\text { Loss }\end{array}$} \\
\hline & $\mathrm{R}$ & $T$ & $\mathrm{R}$ & $T$ & $\mathrm{R}$ & $T$ & $\mathrm{R}$ & $T$ \\
\hline$(\mathrm{mm})$ & \multicolumn{6}{|c|}{ 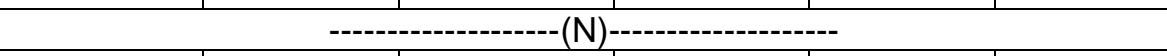 } & \multicolumn{2}{|c|}{$(\%)$} \\
\hline 0.2 & $360(15.0)$ & $297(21.6)$ & $216(18.2)$ & $120(26.4)$ & 144(13.4) & $177(26.3)$ & 40 & 51 \\
\hline 0.3 & $815(9.7)$ & $737(12.0)$ & $520(23.4)$ & $401(9.4)$ & 295(17.1) & $335(30.5)$ & 36 & 46 \\
\hline 0.4 & $1423(12.3)$ & $988(13.3)$ & $971(18.3)$ & $640(16.4)$ & 452(10.2) & $348(22.3)$ & 32 & 35 \\
\hline 0.5 & $2155(17.7)$ & $1439(7.1)$ & $1478(20.3)$ & 952(16.5) & $678(14.6)$ & $487(14.4)$ & 31 & 34 \\
\hline
\end{tabular}

Initial contact force: refers to the maximum load at the beginning of relaxation; Final contact force: refers to the load after $3 \mathrm{~h}$ relaxation; Loss: refers to the difference between initial load and final load; Ratio of loss: refers to the ratio of loss and initial contact force; COV: refers to coefficient of variation; $\mathrm{R} / \mathrm{T}$ : refers to orientation of tenon in radial/tangential orientations.

Further studies will pay attention to other mechanical properties of mortise-andtenon joints. Such as deformations of mortise and tenon and creep behaviors of joints. Besides, the relationships between contact force and withdrawal force capacity and bending moment capacity will be studied.

\section{CONCLUSIONS}

1. The contact force relaxation behavior of joints with tenons in different grain orientations and different tenon fits were studied by a new method put forward in this paper. The results suggest that the initial and final contact force of joints with tenons in radial grain orientations were all bigger than that in tangential grain orientations in the same tenon fit.

2. The fitting equations worked out in this paper were able to predict the contact force of joints with tenons in radial and tangential grain orientations, and the errors were all within $20 \%$.

3. The ratio of loss for contact force of joints with tenons in radial grain orientations were bigger than those with tenons in tangential orientations, and the ratio of loss decreased from $51 \%$ to $31 \%$ with tenon fits increasing from $0.2 \mathrm{~mm}$ to $0.5 \mathrm{~mm}$ with an increment of $0.1 \mathrm{~mm}$.

4. The method put forward in this paper was capable of predicting the contact force relaxation of mortise-and-tenon joints.

\section{ACKNOWLEDGMENTS}

This study was supported by A Priority Academic Program Development of Jiangsu Higher Education Institutions (PAPD). 


\section{REFERENCES CITED}

Diler, H., Acar, M., Balikci, E., Demirci, S., and Erdil, Y. Z. (2017). "Withdrawal force capacity of T-type furniture joints constructed from various heat-treated wood species," BioResources 12(4), 7466-7478. DOI: 10.15376/biores.12.4.7466-7478

Eckelman, C. A. (1971). "Bending strength and moment rotation characteristics of twopin moment resisting dowel joints," Forest Prod. J. 21(3), 35-39.

Erdil, Y. Z., Kasal, A., and Eckelman, C. A. (2005). "Bending moment capacity of rectangular mortise and tenon furniture joints," Forest Prod. J. 55(12), 209-213. WOS: 000234046900036.

Hill, M., and Eckelman, C. A. (1973). "Flexibility and bending strength of mortise and tenon joints," Furniture Design and Manufacturing 45(1), 54-61.

Hu, W. G., Bai, J., and Guan, H. Y. (2017). "Investigation on a method of increasing mortise and tenon joint strength of fast growing wood," J. Beijing For. University 39(4), 101-107. [In Chinese with summary in English.] DOI: 10.13332/j.10001522.20160400

Hu, W. G., and Guan, H. Y. (2017a). "Investigation on withdrawal capacity of mortise and tenon joint based on friction properties," J. Forestry Eng. 2(04), 158-162. [In Chinese with summary in English.] DOI: 10.13360/j.issn.2096-1359.2017.04.025

Hu, W. G., and Guan, H. Y. (2017b). "Experimental and numerical study on optimization design of stretcher positions," Wood research 62(4), 575-586.

Hu, W. G., and Guan, H. Y. (2017c). "Study on elastic modulus of beech in different stress states," J. For. Eng. 2(06), 36-41. [In Chinese with summary in English.] DOI: 10.13360/j.issn.2096-1359.2017.06

Kasal, A., Smardzewski, J., Kuskun, T., and Erdil, Y. Z. (2016). "Numerical analyses of various sizes of mortise and tenon furniture joints," BioResources 11(3), 6836-6853. DOI: $10.15376 /$ biores.11.3.6836-6853

Li, S. X., Liu, W. J., and Sun, D. L. (2014). “Comparative study on corner joints strength of fast-growing Pinus massoniana wood furniture," J. Cent. South Univ. For. Technol. 34(2), 122-126. [In Chinese with summary in English.] DOI: 10.14067/j.cnki.1673923x.2014.02.001

Mohammad, D., and Ghanbar, E. (2014). "Finite element analysis of stress and strain distributions in mortise and loose tenon furniture joints," J. For. Res. 25(3), 677-681. DOI: $10.1007 / \mathrm{s} 11676-014-0507-5$

Ratnasingam, J., and Iorasn, F. (2013). "Effect of adhesive type and glue-line thickness on the fatigue strength of mortise and tenon furniture joints," Eur. J. Wood Wood Prod. 71(1), 819-821. DOI: 10.1007/s00107-013-0724-1

Smardzewski, J., (2002). "Strength of profile-adhesive joints," Wood Sci. Technol. 36(2), 173-183. DOI: 10.1007/s00226-001-0131-3

Smardzewski, J., and Lewandowski, W. (2014). "Elasticity modulus of cabinet furniture joints," Materials and Design 60(8), 260-266. DOI: 10.1016/j.matdes.2014.03.066

Smardzewski, J., and Papuga, T. (2004). "Stress distribution in angle joints of skeleton furniture," Electron. J. Polish Agr. Univ. Wood Technol. 7(1).

Sparkes, A. (1968). The Strength of Mortise and Tenon Joints, Furniture Industry Research Association, Stevenage, Hertfordshire, UK.

Tankut, A. N., and Tankut, N. (2005). "The effects of joint forms (shape) and dimensions on the strengths of mortise and tenon joints," Turkish J. Agr. For. 29, 493-498.

Wang, Y., and Lee, S. H. (2014). "Design and analysis on interference fit in the 
hardwood dowel-glued joint by finite element method," Procedia Engineering 79, 166-172. DOI: 10.1016/j.proeng.2014.06.326

Zaborsky, V., Boruvka, V., Kasickova, V., and Ruman, D. (2017). "Effect of wood species, adhesive type and annual ring directions on the stiffness of rail to leg mortise and tenon furniture joints," BioResources 12(4), 7016-7031. DOI: 10.15376/biores.12.4.7016-7031

Zhong, S. L., and Guan, H. Y. (2007). "Relationship between optimal value of interference fit and wood density in oval-tenon joint," China For. Sci. Technol. 21(2), 57-59. [In Chinese with summary in English.]

Article submitted: December 6, 2017; Peer review completed: February 20, 2018; Revised version received and accepted: March 9, 2018; Published: June 5, 2018.

DOI: 10.15376/biores.13.3.5608-5616 